\title{
A novel electron transfer flavoprotein dehydrogenase (ETFDH) gene mutation identified in a newborn with glutaric acidemia type II: a case report of a Chinese family
}

Mingcai Ou', Lin Zhu², Yong Zhang ${ }^{3}$, Yaguo Zhang ${ }^{1}$, Jingyao Zhou' ${ }^{1}$, Yu Zhang ${ }^{1}$, Xuelian Chen ${ }^{1}$, Lijuan Yang , Ting $\mathrm{Li}^{1}$, Xingyue Su${ }^{1}$, Qi Hu${ }^{1^{*+}}$ and Wenjun Wang ${ }^{2^{*+}}$

\begin{abstract}
Background: Glutaric acidemia type II (GA II) or multiple acyl-CoA dehydrogenase deficiency (MADD, OMIM 231680) is an inherited autosomal recessive disease affecting fatty acid, amino acid and choline metabolism, due to mutations in one of three genes namely, electron transfer flavoprotein alpha-subunit, ETFA, electron transfer flavoprotein $\beta$-subunit, ETFB and electron transfer flavoprotein dehydrogenase, ETFDH. Currently, few studies have reported genetic profiling of neonatal-onset GA II. This study aimed to identify the genetic mutations in a Chinese family with GA II.

Case presentation: We reported a case of GA II with purulent meningitis and septicemia and identified a novel ETFDH gene mutation in a female infant. The patient developed an episode of hypoglycemia and hypotonicity on the postnatal first day. Laboratory investigations revealed elevations of multiple acylcarnitines indicating glutaric acidemia type II in newborn screening analysis. Urinary organic acids were evaluated for the confirmation and revealed a high glutaric acid excretion. Genetic analysis revealed two mutations in the ETFDH gene (c.623_626 del / c. $1399 \mathrm{G}>$ C), which were considered to be the etiology for the disease. The novel mutation c.623_626 del was identified in the proband infant and her father, her mother was carriers of the mutation c.1399G > C.

Conclusions: A novel variant (c.623_626 del) and a previously reported missense (c.1399G > C) in the ETFDH gene have been identified in the family. The two variants of ETFDH gene identified probably underlie the pathogenesis of Glutaric acidemia type II in this family, and also enlarge ETFDH genotype-phenotype correlations spectrum.
\end{abstract}

Keywords: Glutaric acidemia type II, Multiple acyl-CoA dehydrogenase deficiency, ETFDH, Neonatal-onset

\footnotetext{
*Correspondence: 109118386@qq.com; wangwenjun@biosan.cn

${ }^{\dagger} \mathrm{Qi} \mathrm{Hu}$ and Wenjun Wang contributed equally to this work.

'Department of Neonatal screen, Sichuan Provincial Hospital for Women and Children, Chengdu 610000, Sichuan Province, China

${ }^{2}$ Hangzhou Genuine Clinical Laboratory Co. Ltd, 859 Shixiang West Road, Hangzhou 310007, Zhejiang Province, China

Full list of author information is available at the end of the article
}

(c) The Author(s). 2020 Open Access This article is licensed under a Creative Commons Attribution 4.0 International License, which permits use, sharing, adaptation, distribution and reproduction in any medium or format, as long as you give appropriate credit to the original author(s) and the source, provide a link to the Creative Commons licence, and indicate if changes were made. The images or other third party material in this article are included in the article's Creative Commons licence, unless indicated otherwise in a credit line to the material. If material is not included in the article's Creative Commons licence and your intended use is not permitted by statutory regulation or exceeds the permitted use, you will need to obtain permission directly from the copyright holder. To view a copy of this licence, visit http://creativecommons.org/licenses/by/4.0/ The Creative Commons Public Domain Dedication waiver (http://creativecommons.org/publicdomain/zero/1.0/) applies to the data made available in this article, unless otherwise stated in a credit line to the data. 


\section{Background}

Glutaric acidemia type II (GA II), also known as multiple acyl-CoA dehydrogenase deficiency, is an autosomal recessive inborn error of amino acid and fatty acid metabolism [1]. GA II is a disorder with a heterogeneous etiology. The majority of patients show electron transfer flavoprotein (ETFA, ETFB) or ETF dehydrogenase (ETFDH) gene mutations [2]. However, some researchers recently identified defects in the FAD synthase gene (FLAD1) involved in GA II onset [3, 4]. The ETF/ETFDH deficiencies are responsible for multiple defects of the dehydrogenation system because they block not only fatty acid oxidation, but also the oxidation of branched-chain amino acids and glutaryl-CoA on the catabolic pathway of lysine, hydroxylysine, and tryptophan [5]. The genes for ETF $\alpha$, ETF $\beta$ and ETFDH proteins (ETFA, ETFB, and ETFDH, respectively) were mapped to $15 \mathrm{p} 23-25,19 \mathrm{q} 13.1$ and $4 \mathrm{q} 33$, respectively. Since one of the three genes is affected in GA II, it is essential to accumulate information on genetic mutations to determine any genotype/phenotype correlation and to identify defective enzymes for an accurate diagnosis/prenatal diagnosis of GA II.

The heterogeneous clinical features of patients with GA II fall into three subclasses: two neonatal-onset forms (types I/II) and a late-onset form (type III) [6], neonatal form type I with congenital anomalies (most commonly cystic or dysplastic kidneys) [1]; neonatal form type II without congenital anomalies; and late onset form with myopathic phenotype and rarely metabolic acidosis [7]. Neonatal onset form is usually fatal and characterized by severe non-ketotic hypoglycemia, metabolic acidosis, excretion of large amounts of fatty acid, and amino acidderived metabolites with congenital anomalies [8]. In addition to hypoglycemia and metabolic acidosis, routine laboratory findings may include hyperammonemia and elevated liver transaminases, cardiomyopathy may be present in some cases. Pathologic abnormalities include fatty infiltration of the liver, heart, and kidneys [1]. Treatment consists of a diet low in protein and fat together with carnitine, ubiquinone, and riboflavin supplementation. Most neonatal-onset patients may not survive due to progressive deterioration despite aggressive treatment [1]. Several adult-onset GA II cases have been reported with ETFDH mutations, almost 190 different variations of this gene have been identified [2, 9-16], but few ETFDH mutations have been described in neonatal-onset GA II patients $[17,18]$. In the present study, we found a novel variant (c.623_626 del) of the ETFDH gene in the proband by targeted capture and sequencing. The proband was diagnosed with neonatal onset GA II and presented with poor feeding, hypotonia, seizures, severe lactic acidosis, purulent meningitis and septicemia and died on the 24 day of life. We present detailed clinical data and further delineate the phenotype associated with this disease.

\section{Materials and methods}

Blood tandem mass spectrometric analysis

Filter-paper dried blood-spot sample of the patient was pretreated with the NeoBase Non-derivatized MS/MS Kit (Perkin Elmer Life and Analytical Sciences, Turku, Finland), amino acid levels on the dried blood spot was analyzed by liquid chromatography-tandem mass spectrometry (ACQUITY TQD, Waters, Milford, MA, USA).

\section{Urea organic acidemia analysis}

The urine sample was collected and the urine organic acid was analyzed with GC-MS (7890B/5977A, Agilent Technologies, Santa Clara, CA, USA) [19].

\section{Genotyping by next-generation sequencing (NGS)}

Genomic DNA was extracted from dried blood spots or peripheral whole blood of the patient and her parents, and highthroughput sequencing (Illumina Next seq 500) of inherited metabolic diseases-related genes were performed after library preparation, solution hybridization, and beads capture to identify potential disease-causing gene mutations.

\section{Validation mutations by sanger sequencing}

Sanger sequencing was used to validate the identified variants of the proband and her family members. Genomic DNA was amplified using custom oligonucleotide primers. PCR amplification of variants was conducted using Phanta Max Master Mix (Vazyme, China). After the purification of PCR products, sequencing analysis was performed.

\section{Bioinformatics analysis}

We checked the novel variant in frequently used databases such as the Human Gene Mutation Database (http://www. hgmd.cf.ac.uk/ac/index.php), ClinVar (https://www.ncbi. nlm.nih.gov/clinvar/), ExAC consortium (http://exac. broadinstitute.org/), and 1000 Genome Project database (http://www.1000genomes.org/). The variant was further assessed for possible pathogenicity using several bioinformatic programs including SIFT, PolyPhen-2, and MutationTaster. The effect of ETFDH protein domain was predicted by the UniProt database (https://www.uniprot. org/uniprot/Q16134).

\section{Case presentation}

The female proband was born at full-term to nonconsanguineous parents after an uneventful pregnancy as the first child of the family. The infant was delivered by cesarean section due to fetal distress with a 25 years old mother and her family had no history of metabolic diseases. The birth weight was $3650 \mathrm{~g}$ and initial physical examination revealed a healthy infant with no dysmorphic features. 
Table 1 Dried blood spot acylcarnitine results in each separate test

\begin{tabular}{llll}
\hline Blood acylcarnitine concentrations $(\mu \mathrm{mol} / \mathrm{L})$ & Patient first testing & Reference range \\
\hline Free carnitine (C0) & 9.77 & 10.98 & $9-50$ \\
Acetylcarnitine (C2) & 2.04 & 8.48 & $2-50$ \\
Propionylcarnitine (C3) & 0.08 & 0.40 & $0-4$ \\
Butyrlycarnitine (C4) & $\mathbf{2 . 2 8}$ & $\mathbf{3 . 9 2}$ & $0-0.45$ \\
Isovalerylcarnitine (C5) & $\mathbf{0 . 7 1}$ & $\mathbf{0 . 7 9}$ & $0-0.4$ \\
Glutarylcarnitine (C5DC) & $\mathbf{0 . 4 2}$ & $\mathbf{0 . 8 5}$ & $0-0.2$ \\
Hexanoylcarnitine (C6) & $\mathbf{0 . 2 0}$ & $\mathbf{0 . 7 8}$ & $0-0.1$ \\
Octanoylcarnitine (C8) & $\mathbf{0 . 4 2}$ & $\mathbf{1 . 3 6}$ & $0.01-0.15$ \\
Decanoylcarnitine (C10) & $\mathbf{0 . 3 1}$ & $\mathbf{0 . 6 2}$ & $0-0.25$ \\
Dodecanoylcarnitine (C12) & $\mathbf{0 . 7 4}$ & $\mathbf{0 . 6 2}$ & $\mathbf{1 . 1 7}$ \\
Tetradecanoylcarnitine (C14) & $\mathbf{1 . 6 9}$ & $\mathbf{2 . 6 2}$ & 0.35 \\
Hexadecanoylcarnitine (C16) & $\mathbf{8 . 4 6}$ & $\mathbf{9 . 6 3}$ & $\mathbf{0 . 5}$ \\
Octadecenoylcarnitine (C18) & $\mathbf{2 . 3 4}$ & $\mathbf{2 . 2 2}$ & $0.25-2$
\end{tabular}

Black bold in the table indicates high acylcarnitine concentrations level compared with reference

The newborn was transferred to the neonatal intensive care unit due to poor sucking and response. Laboratory analyses found hypoglycemia $(0.06 \mathrm{mmol} / \mathrm{L}$, normal $3.9-6.1$ $\mathrm{mmol} / \mathrm{L}$ ) and metabolic acidosis based on the arterial blood gas results, including $\mathrm{pH} 7.342, \mathrm{pCO}_{2} 17.7 \mathrm{mmHg}, \mathrm{pO}_{2} 77$ $\mathrm{mmHg}, \mathrm{SO}_{2} 95 \%$, and $\mathrm{BE}-16 \mathrm{mmol} / \mathrm{L}$ (reference ranges: arterial $\mathrm{pH} 7.35-7.45, \mathrm{pCO}_{2} 35-45 \mathrm{mmHg}, \mathrm{pO}_{2} 60-90 \mathrm{mmHg}$, $\mathrm{SO}_{2} 95-98 \%$, and $\left.\mathrm{BE} 0 \pm 3 \mathrm{mmol} / \mathrm{L}\right)$. The hypoglycemia and acidosis were treated with glucose and sodium bicarbonate, respectively. Blood analyzer showed the number of white blood cells and neutrophils was increased, and cerebrospinal fluid albumin protein was also elevated. Combined with laboratory analyses and clinical symptoms of the infant with fever, poor feeding, hypotonia, seizures, she was diagnosed with purulent meningitis and septicemia and treatment of ceftriaxone. Transcranial doppler sonography revealed that hemorrhage has occurred. On the fourth day, she occurred fever again with poor feeding, hypotonia, laboratory results with elevated C-reactive protein, after changed meropenem antibiotics and treatment her temperature back to normal but also with hypotonia, poor response, a brain MRI confirmed arachnoid cyst in this case. After 2 weeks, the patient significantly decreased responsiveness and poor feeding, after that she was discharged from hospital with the request of her family.

An expanded newborn screening (NBS) sample obtained on the third day after birth was reported to be positive for glutaric acidemia type II with elevations of multiple acylcarnitines. In particular, $\mathrm{C} 4$ butyrylcarnitine levels were extremely high, accompanied by elevated $\mathrm{C} 5$, C6, C8, C10, C14, C16, C18, and C5-DC glutaryl carnitine levels. Second-tier NBS testing and urinary organic acids were performed to confirm the infant was positive for GA II. The acylcarnitine profile of two tests is shown in Table 1. Glutaric acid excretion was extremely high with increased levels of OX-2-acetoacetic acid, isovalanyl glycine-2, 2-hydroxy isobutyric acid-2, adipic acid.

Genetic analysis revealed two different mutations in the ETFDH gene of the infant [NM_004453.2 c.1399 G > C (p.G467R) and c.623_626 del (p.D208Vfs*3), compound heterozygote]. The mutation c. $1399 \mathrm{G}>\mathrm{C}$ has been reported in HGMD (CM093457) and predicted to be deleterious in silico by SIFT, Polyphen-2, and MutationTaster. These two variants have not been previously reported in the databases, ClinVar, ExAC, and 1000

Table 2 Analysis and in silico prediction of the ETFDH gene variants of the infant

\begin{tabular}{|c|c|c|c|c|c|c|c|c|c|c|c|c|c|c|}
\hline No. & Location & $\begin{array}{l}\text { Nucleotide } \\
\text { change }\end{array}$ & $\begin{array}{l}\text { Protein } \\
\text { change }\end{array}$ & $\begin{array}{l}\text { Parental } \\
\text { origin }\end{array}$ & $\begin{array}{l}\text { Type of } \\
\text { change }\end{array}$ & Novelty & SIFT & $\begin{array}{l}\text { PolyPhen- } \\
2\end{array}$ & $\begin{array}{l}\text { Mutation } \\
\text { Taster }\end{array}$ & HGMD & ClinVar & $\begin{array}{l}\text { Freq in } \\
1000 \\
\text { Genome }\end{array}$ & $\begin{array}{l}\text { Freq } \\
\text { in } \\
\text { ExAC }\end{array}$ & Reference \\
\hline 1 & Exon 6 & $\begin{array}{l}\text { c.623_626 } \\
\text { del }\end{array}$ & $\begin{array}{l}\text { p.Asp208Val } \\
\text { fs }^{*} 3\end{array}$ & paternal & het & novel & N/A & N/A & 1 & ND & ND & ND & ND & $\begin{array}{l}\text { This } \\
\text { study }\end{array}$ \\
\hline 2 & Exon 11 & c.1399 G >C & p.Gly467Arg & maternal & het & reported & 0 & 1 & 1 & $\begin{array}{l}\text { CM } \\
093457\end{array}$ & ND & ND & ND & [20] \\
\hline
\end{tabular}

The reference sequence used in this study was based on the NCBI37/hg19 assembly of the human genome. NM_004453.2 was employed as reference sequence for ETFDH. ND no data, N/A not available 


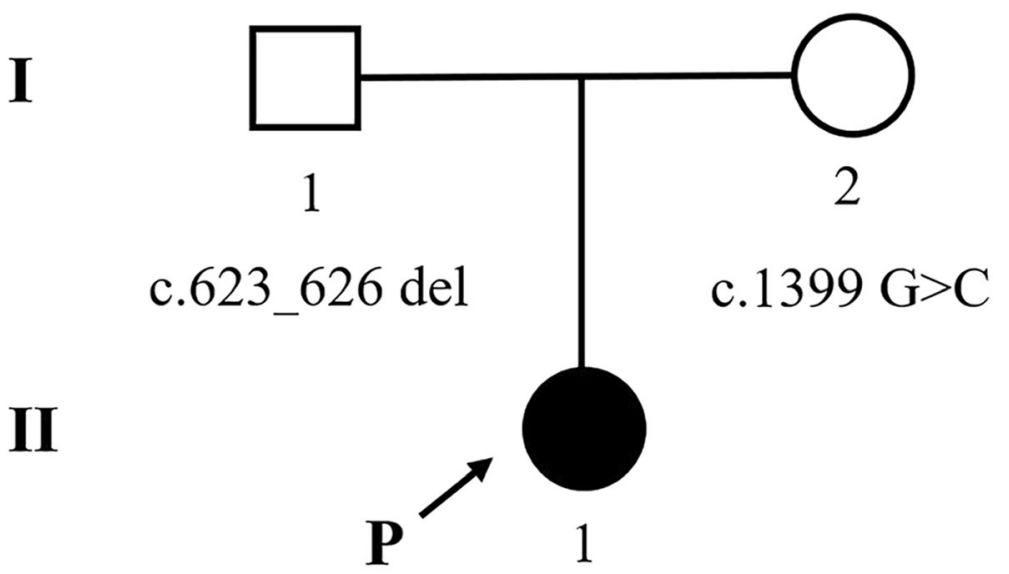

\section{c. $623 \quad 626 \mathrm{del}$ \\ c. $1399 \mathrm{G}>\mathrm{C}$}

Fig. 1 ETFDH gene mutations determined by NGS in infant patient and her family. (The filled black symbols represent the affected members and the arrow denotes the proband)

Genomes (Table 2). According to ACMG guidelines, the novel variant c.623_626 del was classified as a likely pathogenic mutation, which was identified in the proband infant and her father, the proband's mother was carriers of the mutation (c.1399G > C) and these mutations were considered to be the cause of the disease, the pedigree is shown in Fig. 1. These two variants of this family were validated by Sanger sequencing (Fig. 2).

\section{Discussion and conclusions}

Glutaric acidemia type II, also known as multiple acylcoenzyme A dehydrogenase deficiency (MADD) was first described in 1976 [19]. GA II is an autosomal recessive disorder resulting from a deficiency of electron transfer flavoprotein (ETF) or ETF dehydrogenase (ETFDH) that manifests from most severe neonatal to late-onset forms. Neonatal-onset form patients may develop severe

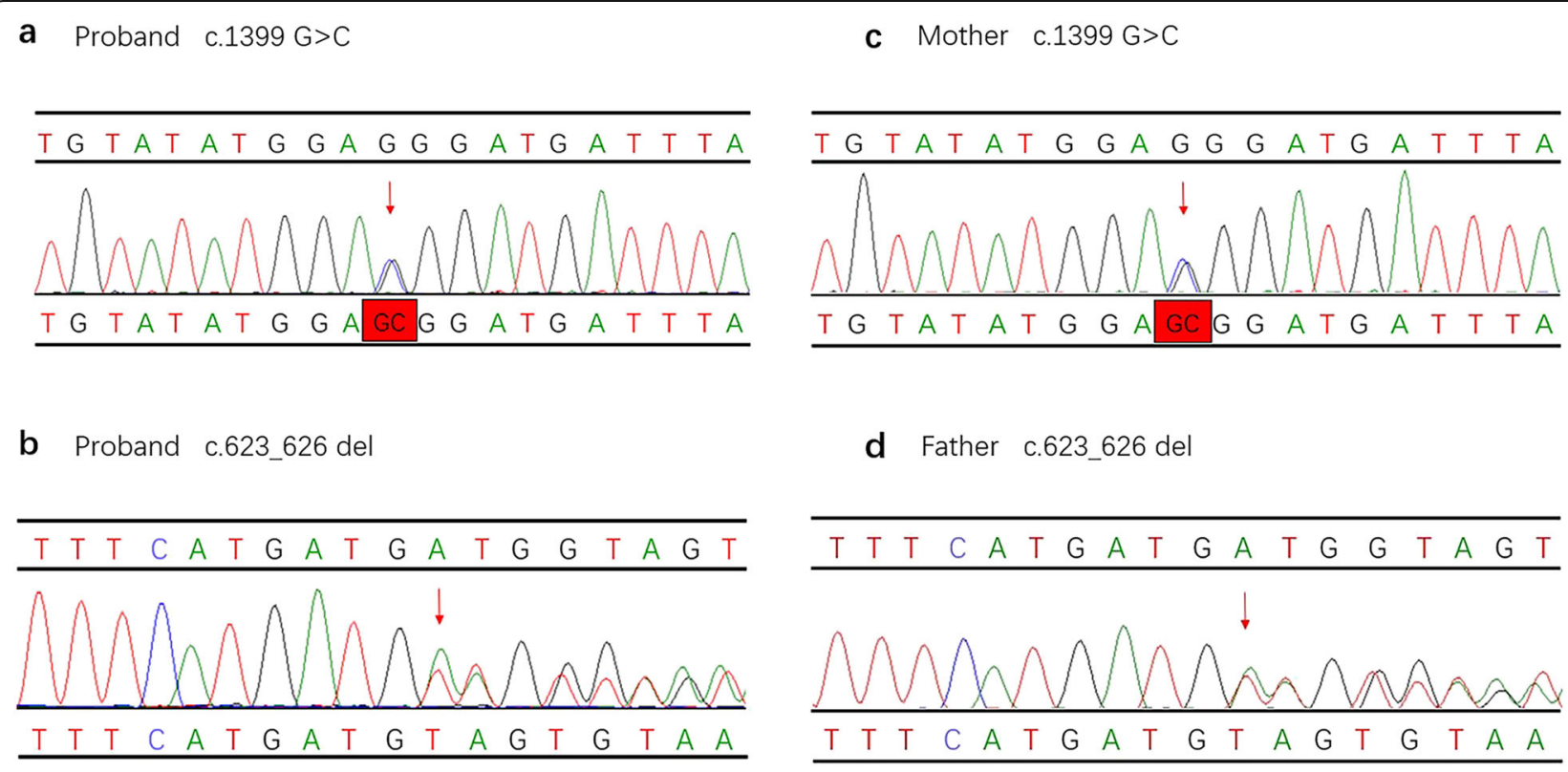

Fig. 2 Sequence analysis of ETFDH gene mutation in proband and her parents. The heterozygous variant c.1399G > C in exon 11 was identified in proband (a) and her mother (c); the variant c.623_626 del in exon 6 was identified in proband (b) and her father (d) 
respiratory failure, cardiomyopathy, hypotonia, metabolic acidosis, and profound hypoglycemia soon after birth, which corresponds with short life expectancy [2]. Variants of the ETFDH gene, which contains 13 exons and about $36 \mathrm{~kb}$ long, are one cause of GA II. To date, more than 190 ETFDH mutations have been reported in Clinvar, with missense mutation as the most common type, of which the major GA II cases were adult-onset, but few disease-causing mutations have been described in neonatal form. Recent reports including this research showed clinical phenotypes in three neonatal-onset patients with ETFDH gene mutations (Table 3), F.H. van der Westhuizen et al. [17] reported that a newborn with homozygous variants (c.1067G > A) presented with multiple congenital anomalies including cardiac lesions and hydronephrosis. Vieira et al. [18] described an infant with homozygous variants (c.1141G > C) who presented with profound hypotonia and hepatomegaly, the brain MRI displayed white matter signal abnormalities. Gao et al. [21] reported a Chinese male infant (14 days) with GA II. The results of tandem mass spectrometry showed that C14:1, C8, C6, C10, and C12 increased. Exon sequencing was performed on this infant and revealed compound heterozygous variants in the ETFDH gene c. $992 \mathrm{~A}>\mathrm{T}$ and c.1450 T > C. After 20 months, the newborn was diagnosed as a late-onset form (type III)

Table 3 Summary of clinical, biochemical and genetic features associated with ETFDH variants of neonatal GA II

\begin{tabular}{|c|c|c|c|}
\hline & Patient1 & Patient2 & Patient3 \\
\hline Gender & Male & Male & Female \\
\hline Origin & Caucasian Afrikaner & Kurdish origin & Chinese \\
\hline $\begin{array}{l}\text { Age of onset/ } \\
\text { death }\end{array}$ & Week 1/Day 9 & 3 months/ 34 months & Day 1/ Day 24 \\
\hline $\begin{array}{l}\text { Main clinical } \\
\text { features }\end{array}$ & $\begin{array}{l}\text { Intra-uterine growth } \\
\text { retardation } \\
\text { Multiple congenital } \\
\text { anomalies: } \\
\text { - Cardiac lesions } \\
\text { - Hydronephrosis } \\
\text { Riboflavin unresponsive }\end{array}$ & $\begin{array}{l}\text { Profound hypotonia and hepatomegaly. } \\
\text { White matter signal abnormalities on brain MRI } \\
\text { Riboflavin responsive }\end{array}$ & $\begin{array}{l}\text { Poor sucking and response, fever, } \\
\text { hypotonia, seizures } \\
\text { Purulent meningitis and septicemia }\end{array}$ \\
\hline \multicolumn{4}{|c|}{ Routine Biochemistry } \\
\hline $\begin{array}{l}\text { - Metabolic } \\
\text { acidosis }\end{array}$ & Present & Not performed & Present \\
\hline - Glucose & Normal- $\downarrow$ & $\downarrow$-Normal & $\downarrow$ \\
\hline - Ammonia & $\uparrow$ & $\uparrow$ & $\uparrow$ \\
\hline $\begin{array}{l}\text { - Urine } \\
\text { ketones }\end{array}$ & Absent & Not performed & Not performed \\
\hline $\begin{array}{l}\text { - Lactate/ } \\
\text { pyruvate }\end{array}$ & Normal- $\uparrow$ & $\uparrow$ & $\uparrow$ \\
\hline Transaminases & $\uparrow G G T, A S T$ & $\mathrm{ALT} \uparrow$ & $\mathrm{GGT}, \mathrm{AST}, \mathrm{ALP} \uparrow$ \\
\hline Creatine kinase & Not performed & normal & Not performed \\
\hline CBC findings & Pancytopenia & Not performed & White blood cells and neutrophils $\uparrow$ \\
\hline \multicolumn{4}{|c|}{ Metabolic findings } \\
\hline Acylcarnitines & $\begin{array}{l}\uparrow C 4-, C 5, C 5-D C \\
\text { Low free carnitine }\end{array}$ & $\begin{array}{l}\uparrow C 8, C 10, C 12, C 14 \\
\text { Normal free carnitine }\end{array}$ & $\begin{array}{l}\uparrow C 4-, C 5, C 5-D C, C 6, C 8, C 10, C 12, C 14, \\
\text { C16, C18 }\end{array}$ \\
\hline Organic acids & $\begin{array}{l}\uparrow \text { Ethylmalonic acid, } \\
\text { Dicarboxylic acids, } \\
\text { Glycine conjugates, 2- } \\
\text { Hydroxryglutaric acid } \\
\text { Lactic acid, Krebs cycle } \\
\text { intermediates }\end{array}$ & $\begin{array}{l}\text { } \text { Glutaric acid, Dicarboxylic aciduria } \\
2 \text {-Hydroxyglutaric acid }\end{array}$ & $\begin{array}{l}\uparrow \text { Glutaric acid, OX-2-Acetoacetic acid, } \\
\text { 2-Hydroxy isobutyric acid-2, adipic acid, } \\
\text { isovalanyl glycine-2, }\end{array}$ \\
\hline Amino acids & $\begin{array}{l}\text { General amino aciduria with } \\
\uparrow \\
\text { Sarcosine }\end{array}$ & $\begin{array}{l}\uparrow \text { Threonine, serine, asparagine, glycine, alanine, } \beta \text { - } \\
\text { aminoisobutyric acid, and lysine. }\end{array}$ & $\uparrow$ Citrulline \\
\hline $\begin{array}{l}\text { ETFDH } \\
\text { variants }\end{array}$ & c.1067G > A/ c.1067G > A & c. $1141 G>C /$ c. $1141 G>C$ & c.1399 G > C/ c.623_626 del \\
\hline Reference & $\begin{array}{l}\text { F.H. van der Westhuizen et al. } \\
{[11]}\end{array}$ & Vieira et al. [12] & Our study \\
\hline
\end{tabular}


without typical clinical symptoms and congenital anomalies. The patient in our study had severe hypoglycemia and with clinical symptoms of fever, poor feeding, hypotonia, the diagnosis was achieved by examination in the CSF and the expanded newborn screening analysis. As a result of these findings, together with MRI examination, the patient was diagnosed with GA II complicated purulent meningitis and septicemia. Purulent or bacterial meningitis is characterized by the invasion and growth of bacteria in the CSF, which is more frequent during the neonatal period than at any other period of life [22]. The clinical features of neonatal bacterial meningitis are nonspecific, CSF study through lumbar puncture is the only way to confirm the diagnosis of meningitis and we examined this case. We genetically analyzed this rare disease in a Chinese female infant and revealed two different mutations (c. $1399 \mathrm{G}>\mathrm{C} / \mathrm{c} .623$ 626 del) in the ETFDH gene. The c.1399 G>C mutation was first reported in riboflavin-responsive lipid-storage myopathy male patient, whose age-onset was 12 years [23]. It has been reported in a riboflavin-responsive multiple AcylCoA dehydrogenation deficiency late-onset Chinese patient with the c.1399 G > A mutation, western blot analysis revealed a significant reduction of ETF: QO (ETFubiquinone oxidoreductase) expression encoded by the ETFDH gene, which was more than $90 \%$ decrease in mutant protein compared with control [20]. The c.623_626 del mutation was first reported in this study, the variant resulting in the premature termination of the protein decreased. According to the UniProt database analysis, the termination of the protein at position 210 affected functional domains of ETFDH, including FAD/NAD(P)binding domain (protein position 40-343 and 368-514), $4 \mathrm{Fe}-4 \mathrm{~S}$ ferredoxin-type, iron-sulphur binding domain (protein position 577-606), which may affect structure and function of protein and contributed to GA II. Pedigree analysis revealed that her mother and father were carriers of the mutations (c. $1399 \mathrm{G}>\mathrm{C} / \mathrm{c} .623$ 626 del) respectively, the ETFDH gene mutation of the infant was compound heterozygote and may affect ETFDH expression resulted in GA II.

The discovery of novel variants further expands the spectrum of known ETFDH mutations in humans and provide molecular evidence for the etiological diagnosis of the patient with GA II as well as for the genetic counseling and prenatal diagnosis in the family.

\section{Abbreviations}

ACMG: American College of Medical Genetics; CSF: Cerebrospinal Fluid; GA II: Glutaric acidemia type II; MRI: Magnetic resonance imaging; NBS: Newborn screening; PDB: Protein data bank

\section{Acknowledgements}

The authors thank all family members for their cooperation during this work.

\section{Authors' contributions}

MCO conceived and designed the work; QH, JYZ, YZ1, XLC and LY performed the experiments, MCO, YZ2, QH, YGZ, TL and XYS analyzed the data. WJW, LZ and $\mathrm{MCO}$ wrote the manuscript. All authors read and approved the final manuscript.

\section{Funding}

Not applicable.

\section{Availability of data and materials}

All relevant data are included in the manuscript. The datasets used and/or analyzed during the current study are available from the corresponding author upon request.

Ethics approval and consent to participate

The study was approved by the Ethics Committee of Sichuan Provincial Hospital for Women and Children. Informed consent was obtained from the parents of the study subject.

\section{Consent for publication}

Written informed consent was obtained from the parents for publication of this Case Report.

\section{Competing interests}

The authors declare that they have no competing interests.

\section{Author details}

${ }^{1}$ Department of Neonatal screen, Sichuan Provincial Hospital for Women and Children, Chengdu 610000, Sichuan Province, China. ${ }^{2}$ Hangzhou Genuine Clinical Laboratory Co. Ltd, 859 Shixiang West Road, Hangzhou 310007, Zhejiang Province, China. ${ }^{3}$ Neonatal unit, Sichuan Provincial Hospital for Women and Children, Chengdu 610000, Sichuan Province, China.

Received: 25 March 2019 Accepted: 10 March 2020

Published online: 11 May 2020

References

1. Angle B, Burton BK. Risk of sudden death and acute life-threatening events in patients with glutaric acidemia type II. Mol Genet Metab. 2008;93(1):36-9.

2. Yamada K, Kobayashi H, Bo R, Takahashi T, Purevsuren J, Hasegawa Y, Taketani T, Fukuda S, Ohkubo T, Yokota T, et al. Clinical, biochemical and molecular investigation of adult-onset glutaric acidemia type II: characteristics in comparison with pediatric cases. Brain and Development. 2016;38(3):293-301.

3. Olsen RK, Konarikova E, Giancaspero TA, Mosegaard S, Boczonadi V, Matakovic L, Veauville-Merllie A, Terrile C, Schwarzmayr T, Haack TB, et al. Riboflavin-responsive and -non-responsive mutations in FAD synthase cause multiple acyl-CoA dehydrogenase and combined respiratory-chain deficiency. Am J Hum Genet. 2016;98(6):1130-45.

4. Ryder B, Tolomeo M, Nochi Z, Colella M, Barile M, Olsen RK, InbarFeigenberg M. A novel truncating FLAD1 variant, causing multiple acyl-CoA dehydrogenase deficiency (MADD) in an 8-year-old boy. JIMD Rep. 2019;45: 37-44.

5. Ersoy EO, Rama D, Unal O, Sivri S, Topeli A. Glutaric aciduria type 2 presenting with acute respiratory failure in an adult. Respir Med Case Rep. 2015;15:92-4.

6. Shioya A, Takuma H, Yamaguchi S, Ishii A, Hiroki M, Fukuda T, Sugie H, Shigematsu Y, Tamaoka A. Amelioration of acylcarnitine profile using bezafibrate and riboflavin in a case of adult-onset glutaric acidemia type 2 with novel mutations of the electron transfer flavoprotein dehydrogenase (ETFDH) gene. J Neurol Sci. 2014;346(1-2):350-2.

7. Domizio S, Romanelli A, Brindisino P, Puglielli C, Conte E, Domizio R, Sgarrella MC, Sabatino G. Glutaric aciduria type II: a case report. Int J Immunopathol Pharmacol. 2005;18(4):805-8.

8. Beresford MW, Pourfarzam M, Turnbull DM, Davidson JE. So doctor, what exactly is wrong with my muscles? Glutaric aciduria type II presenting in a teenager. Neuromuscul Disord. 2006;16(4):269-73.

9. Koppel S, Gottschalk J, Hoffmann GF, Waterham HR, Blobel H, Kolker S. Lateonset multiple acyl-CoA dehydrogenase deficiency: a frequently missed diagnosis? Neurology. 2006;67(8):1519. 
10. Izumi R, Suzuki N, Nagata M, Hasegawa T, Abe Y, Saito Y, Mochizuki H, Tateyama M, Aoki M. A case of late onset riboflavin-responsive multiple acyl-CoA dehydrogenase deficiency manifesting as recurrent rhabdomyolysis and acute renal failure. Intern Med. 2011;50(21):2663-8.

11. Sugai F, Baba K, Toyooka K, Liang WC, Nishino I, Yamadera M, Sumi H, Fujimura $\mathrm{H}$, Nishikawa Y. Adult-onset multiple acyl CoA dehydrogenation deficiency associated with an abnormal isoenzyme pattern of serum lactate dehydrogenase. Neuromuscul Disord. 2012;22(2):159-61.

12. Zhuo Z, Jin P, Li F, Li H, Chen X, Wang H. A case of late-onset riboflavin responsive multiple acyl-CoA dehydrogenase deficiency (MADD) with a novel mutation in ETFDH gene. J Neurol Sci. 2015;353(1-2):84-6.

13. Angelini C, Pennisi E, Missaglia S, Tavian D. Metabolic lipid muscle disorders: biomarkers and treatment. Ther Adv Neurol Disord. 2019;12: 1756286419843359.

14. Grunert SC. Clinical and genetical heterogeneity of late-onset multiple acylcoenzyme A dehydrogenase deficiency. Orphanet J Rare Dis. 2014;9:117.

15. Angelini C, Tavian D, Missaglia S. Heterogeneous phenotypes in lipid storage myopathy due to ETFDH gene mutations. JIMD Rep. 2018;38:33-40.

16. Missaglia S, Tavian D, Moro L, Angelini C. Characterization of two ETFDH mutations in a novel case of riboflavin-responsive multiple acyl-CoA dehydrogenase deficiency. Lipids Health Dis. 2018;17(1):254.

17. van der Westhuizen FH, Smuts I, Honey E, Louw R, Schoonen M, Jonck LM, Dercksen M. A novel mutation in ETFDH manifesting as severe neonatalonset multiple acyl-CoA dehydrogenase deficiency. J Neurol Sci. 2018;384: 121-5.

18. Vieira P, Myllynen P, Perhomaa M, Tuominen H, Keski-Filppula R, Rytky S, Risteli L, Uusimaa J. Riboflavin-responsive multiple acyl-CoA dehydrogenase deficiency associated with hepatoencephalomyopathy and white matter signal abnormalities on brain MRI. Neuropediatrics. 2017;48(3):194-8.

19. Przyrembel H, Wendel U, Becker K, Bremer HJ, Bruinvis L, Ketting D, Wadman SK. Glutaric aciduria type II: report on a previously undescribed metabolic disorder. Clin Chim Acta. 1976;66(2):227-39.

20. Zhu M, Zhu X, Qi X, Weijiang D, Yu Y, Wan H, Hong D. Riboflavin-responsive multiple acyl-CoA dehydrogenation deficiency in 13 cases, and a literature review in mainland Chinese patients. J Hum Genet. 2014:59(5):256-61.

21. Gao A, Qiao LW, Duan CY, Zhao NN, Zhang W, Zhang Q. A novel mutation in the ETFDH gene of an infant with multiple acyl-CoA dehydrogenase deficiency. Zhongguo Dang Dai Er Ke Za Zhi. 2018;20(7):529-33.

22. Kamoun F, Dowlut MB, Ameur SB, Sfaihi L, Mezghani S, Chabchoub I, Hammami A, Aloulou H, Hachicha M. Neonatal purulent meningitis in southern Tunisia: epidemiology, bacteriology, risk factors and prognosis. Fetal Pediatr Pathol. 2015;34(4):233-40.

23. Wen B, Dai T, Li W, Zhao Y, Liu S, Zhang C, Li H, Wu J, Li D, Yan C. Riboflavin-responsive lipid-storage myopathy caused by ETFDH gene mutations. J Neurol Neurosurg Psychiatry. 2010;81(2):231-6.

\section{Publisher's Note}

Springer Nature remains neutral with regard to jurisdictional claims in published maps and institutional affiliations.

Ready to submit your research? Choose BMC and benefit from:

- fast, convenient online submission

- thorough peer review by experienced researchers in your field

- rapid publication on acceptance

- support for research data, including large and complex data types

- gold Open Access which fosters wider collaboration and increased citations

- maximum visibility for your research: over $100 \mathrm{M}$ website views per year

At BMC, research is always in progress.

Learn more biomedcentral.com/submissions 